\title{
Variations in the TNFa gene and their interactions with the IL4R and ILI0 genes in relation to hand osteoarthritis
}

\author{
Satu Hämäläinen ${ }^{*}$, Svetlana Solovieva, Tapio Vehmas, Päivi Leino-Arjas and Ari Hirvonen
}

\begin{abstract}
Background: The development of osteoarthritis $(\mathrm{OA})$ involves inflammation, but the evidence for participation of genes propagating or inhibiting inflammation in the OA process is inconsistent. We investigated the associations of common variants in the TNFa gene, and their interactions with other cytokine genes, with hand OA among Finnish women.

Methods: This cross-sectional study was based on bilateral hand radiographs of 542 female dentists and teachers which were classified according to the presence of OA (radiographic K-L score $\geq 2$ in $\geq 3$ joints) using reference images. The genotypes were determined by PCR-based methods. The degree of pairwise linkage disequilibrium (LD) and haplotypes were constructed and analyzed by the SNPStats software. The associations between four TNFa SNPs and hand OA were tested using logistic regression adjusting for age, occupation, and BMI, and fitting a log-additive model of inheritance. Gene-gene interactions of TNFa SNPs with IL4R and IL10 SNPs were examined by stratified logistic regression analyses. Possible interactions of the TNFa SNPs with variants in the previously reported $I L 1 \beta$ and $I L 6$ genes in influencing hand OA were also explored.
\end{abstract}

Results: Two TNFa polymorphisms ("-1031" and "-863") were associated with hand OA (OR $=1.45,95 \% \mathrm{Cl} 1.01-2.07$ and $1.55,1.06-2.25$, respectively). These associations retained when adjusting further for IL1 $\beta$ " 3954 " and IL6 "174". The TNFa G-A-G haplotype was associated with an increased risk of hand OA $(1.61,1.10-2.37, p=0.01)$. Interactions were observed between TNFa "-1031" and IL4R Ser503Pro, TNFa "-1031" and IL10 "-1082", and TNFa "-863" and IL10 "-1082" SNPs with regard to hand OA ( $p=0.012, p=0.0068$, and $p=0.02$, respectively). The carriage of the TNFa "-1031" minor allele doubled the risk $(2.01,1.26$ - 3.22) only in women with the IL4R Ser/Ser genotype. Similarly, the TNFa "-1031" and "-863" minor alleles were associated with an increased risk of hand OA only in $/ L 10 \mathrm{G} / \mathrm{G}$ or A/A homozygotes (2.54, 1.45-4.47 and 2.60, 1.46-4.62, respectively) but not in heterozygotes (G/A).

Conclusions: Our results suggest that the TNFa gene variants play a role in the etiology of hand OA. In addition, the findings are suggestive of a gene-gene interaction of the TNFa with IL4R and IL 10 genes.

Keywords: Tumor necrosis factor alpha, Gene polymorphism, Individual susceptibility, Hand osteoarthritis, Inflammation

\section{Background}

Osteoarthritis (OA) is the most common joint disorder worldwide and rapidly increasing with ageing populations. OA is a dynamic process involving all the structures within the joint, i.e., cartilage, synovial membrane and subchondral bone. It shows clinical heterogeneity in joint numbers and regions involved.

\footnotetext{
* Correspondence: satu.hamalainen@ttl.fi

Finnish Institute of Occupational Health, Centre of Expertise for Health and Work Ability, Topeliuksenkatu 41 a A, Fl-00250 Helsinki, Finland
}

Some patients may have only one site affected (hip, knee, or hand) affected (local OA), while others have clustered joint regions affected in a characteristic distribution (generalized OA) [1].

The hand is among the most frequently affected site in $\mathrm{OA}$ [2]. The prevalence of hand $\mathrm{OA}$ is higher in women than in men over the age of 50 [3]. Although the pathogenesis of hand $\mathrm{OA}$ is largely unknown, familial aggregation and heritability studies indicate a significant genetic role in addition to the involvement of 
mechanical (repetitive joint loading) and lifestyle related factors (e.g. obesity) [3,4].

The development and progression of OA are nowadays believed to involve inflammation [5-8]. Chondrocytes, as well as synovial cells, of OA patients produce increased levels of pro-inflammatory cytokines, which affect metabolism and enhance the catabolism of all joint tissues affected in OA [5]. Among pro-inflammatory cytokines, interleukin-1 $\beta$ (IL1 $\beta$ ) and tumor necrosis factor alpha (TNF $\alpha$ ) seem prominent and of major importance to cartilage destruction as they are synthesized during the OA process [9-11]. In vivo studies have shown that these cytokines can act independently or in concert with other cytokines (e.g. IL6) in the induction and propagation of inflammation [12]. Synthesis of the IL1 $\beta$ and TNF $\alpha$ is inhibited by anti-inflammatory cytokines such as IL4, IL10 and IL13 [13]. On the other hand, expression of cytokine genes like IL1 and TNF $\alpha$ is up-regulated in OA [14].

The gene encoding TNF $\alpha$ is located in the class III region of the major histocompatibility complex (MHC) which is the most gene-dense and polymorphic region of the entire genome [15]. TNF $\alpha$ is driving the inflammatory cascade [5]. IL4 in turn is a cytokine produced by T cells, which plays a major role in immunoglobulin $\mathrm{E}$ (IgE) production. Its signals are conferred to effector cells through binding to the alpha chain of IL4 receptor (IL4R). IL4 and IL4R are expressed by human articular chondrocytes; data suggest that mechanical stimulation induces the release of IL4 by human chondrocytes after the recognition and transduction of the mechanical signal by integrin $[16,17]$. Therefore, the IL4R is an active autocrine or paracrine signaling molecule in a regulatory pathway in the maintenance of human articular cartilage structure and function [16]. Regulation of the structure and function of human articular cartilage occurs by mediating other biochemical responses to mechanical strain, proteoglycan synthesis, or altering the expressions of other extra cellular matrix (ECM) proteins involved in the pathogenesis of OA $[16,17]$.

So far, the evidence for involvement of genes propagating or inhibiting inflammation in the development or progression of OA is inconsistent, and the observed associations were not replicated in an independent population [18]. Most of the previous studies examined the role of a single gene in $\mathrm{OA}$ without taking into consideration the interaction of the genes participating in the regulation of balance between pro- and anti-inflammatory processes. Our group has reported the associations of the IL1 extended haplotype and common IL6 promoter variants with symmetrical DIP OA $[19,20]$.

The aim of the current study was to investigate the associations of common variants in the TNF $\alpha$ gene and their interactions with variants in the IL4R and IL1O genes in relation to hand OA among middle-aged Finnish women, representing two occupations: dentists and teachers. The possible interactions of the $T N F \alpha$ with variants in the $I L 1 \beta$ and IL6 in influencing hand OA were also explored.

\section{Methods}

\section{Study design and participants' selection}

This was a cross-sectional study, samples of which were taken randomly from two occupational groups. The study participants were identified from the registers of the Finnish Dental Association and the Finnish Teachers Trade Union. Four hundred and thirty-six women aged 45 to 63 were randomly selected from both occupational groups (altogether 872 subjects) by using the place of residence (Helsinki or its neighboring cities) as an inclusion criterion. Of those subjects who received the questionnaires in 2002, 542 (62\% of the invited) participated in a clinical examination between October 2002 and March 2003. Of these, 294 (67\% of the invited) were dentists and 248 (57\% of the invited) teachers. Participation in the study was voluntary and based on informed consent. The study was approved by the Hospital District of Helsinki and Uusimaa Ethics Committee for Research in Occupational Health and Safety.

\section{Hand radiography and image analysis}

Both hands of the study participants were radiographed by exposing Kodak X-ray films with Siemens X-ray equipment $(48 \mathrm{kV}, 10 \mathrm{~mA}$, focus film distance $=115 \mathrm{~cm}$; Siemens, Munich, Germany). The analogue radiographs were evaluated by an experienced radiologist who was blinded to the occupation, age, and all health data of the participants. Each distal interphalangeal (DIP), proximal interphalangeal (PIP), and thumb interphalangeal (IP) joint of both hands was graded separately, and classified for the presence of OA using a modified Kellgren and Lawrence (K-L) system [21]; the classification criteria were: grade $0=$ no $\mathrm{OA}$, grade $1=$ doubtful $\mathrm{OA}$, grade $2=$ mild $\mathrm{OA}$, grade $3=$ moderate $\mathrm{OA}$, and grade $4=$ severe $\mathrm{OA}$. The description of reference images used in the classification is given elsewhere [22]. The reliability of the readings was estimated by measuring intra-observer and inter-observer agreements (intraclass correlation) within a limited sample of radiographs and a second participating radiologist. The inter-observer agreement for OA ranged from 0.67 to 0.85 for DIP joints and from 0.39 to 0.61 for PIP joints. The intra-observer agreement for OA ranged from 0.73 to 0.88 for DIP joints and from 0.67 to 0.92 for PIP joints [22].

Participants who had at least three finger joints with radiographic OA of grade 2 to 4 were classified as having hand OA. Otherwise, the participants were classified as not having hand $\mathrm{OA}$. 


\section{Covariates}

Weight was measured without shoes to the accuracy of $0.1 \mathrm{~kg}$. Body mass index $\left[\mathrm{BMI}=\right.$ weight $(\mathrm{kg}) /$ height $\left.(\mathrm{m})^{2}\right]$ was calculated based on weight and self-reported height. BMI data was missing from one participant. Age, occupation, and BMI were considered as possible confounders in the analyses. The variants in the ILI $\beta$ and IL6 that was previously shown to influence hand OA were also included among the covariates.

\section{Genotyping analysis}

Blood samples were taken from each study participant in the clinical examination and stored at $+4^{\circ} \mathrm{C}$ until DNA extraction using a DNA extraction kit (PUREGENE 'DNA Purification Kit; Gentra Systems, Plymouth, MN, USA).

The TNF $\alpha$ "-1031" (rs1799964) and the "-857" (rs1799724) genotypes were determined by the TaqMan ${ }^{\circ}$ SNP Genotyping Assay (Applied Biosystems, C 7514871_10 and C_11918223_10, respectively).

The TNF $\alpha$ "-863" (rs1800630) genotype was determined and the "-857" genotype re-determined by the Pyrosequencing ${ }^{\odot}$ PSQ 96MA SNP/SQA system with PyroMark Assay Design self-designed protocol.

The TNF $\alpha$ "-308" (rs1800629) genotype was determined by PCR-RFLP method with NcoI (New England BioLabs (NEB) $10 \mathrm{U} / \mu \mathrm{L}$ ) restriction enzyme. The primers were from Ozen et al. [23].

In the TNF $\alpha$ "-1031" locus the T-allele was denoted as the wild type allele and the $\mathrm{C}$-allele as the variant allele, in the "-863" and "-857" loci the C-alleles were denoted as the wild type alleles and the $\mathrm{A}$ - and T-allele as the variant alleles, respectively, and in the "-308" locus the G-allele was denoted as the wild type allele and the A-allele as the variant allele.

The IL4R Ser503Pro (1507 T $>$ C, rs1805015) and Ser752Ala (2254 T $>$ G, rs1805016) polymorphisms were genotyped by PCR-based TaqMan ${ }^{\circledR}$ SNP Genotyping Assays (Applied Biosystems, C_234284_1 and C_ 8903091_10 respectively).

The IL10 “-1082” (rs1800896) SNP was genotyped with primers from Koch et al. [24].

An additional file has detailed description about the genotyping (see Additional file 1).

For quality control $10 \%$ of the genotyped samples were blindly repeated with $100 \%$ concordant results. Genotype data was available from all participants.

The earlier published IL1 $\beta$ “3954" (rs1143634), and IL6 "174" (rs1800795) genotyping has been described elsewhere $[19,20]$.

\section{Statistical analysis}

The potential deviation of the allele frequencies from the Hardy-Weinberg equilibrium (HWE) was tested from controls using the chi-square test. The degree of pairwise linkage disequilibrium (LD) for four $T N F \alpha$ SNPs and two IL4R SNPs were calculated using SNPStats software [25]. Haplotypes were constructed and analyzed by the same software.

Logistic regression analysis was used to test the associations between SNPs and hand OA. For each SNP, a logadditive model of inheritance was fitted. To evaluate whether the observed association between the TNF $\alpha$ and OA was modified by variants in other cytokine genes, gene-gene interactions were tested for all TNF $\alpha$ SNPs by stratified logistic regression analyses.

Both crude and adjusted odds ratios (ORs) and their 95\% confidence intervals (CIs) were calculated. The ORs were adjusted for the potential confounding factors, i.e., age (continuous), occupation (dentists vs. teachers), and BMI (continuous). Since the crude and adjusted ORs did not differ significantly, only the adjusted ORs are shown in the results. In addition, the OR's were further adjusted for genetic variants in the IL1 $\beta$ and IL6.

In addition to exploring whether the effect of the $T N F \alpha$ SNPs on hand OA were independent of the genetic variants in the IL1 $\beta$ [19] and IL6 [20], we estimated the individual and joint effects of the TNF $\alpha$ ("-863"), $I L 1 \beta$ and IL6 polymorphisms using the combinations of two dummy $(0,1)$ variables. First, we calculated the sum of the minor alleles of $I L 1 \beta$ and $I L 6$, by summing up the number of minor alleles of two SNPs. This was dichotomized (first dummy variable): $0=$ non-carriers of any minor allele of the IL1 $\beta$ and IL6 and $1=$ carriers of at least one minor allele. For the TNF “-863" SNP we used the dominant model, with the homozygous genotype of the major allele as the reference (second dummy variable).

All analyses were hypothesis driven. The statistical significance of the p-value was defined as the $1 \%$ level. P-values were adjusted for multiple testing using Sidák's method [26]. We used SNPStats software [25] and SPSS 20.0 for the analyses.

\section{Results}

The prevalence of hand OA with at least three affected finger joints was 29.5\%, being higher among teachers (35.5\%) than dentists $(24.5 \%)$ (Table 1). Participants with

Table 1 Description of the samples of female dentists and teachers aged 45-63, living in the metropolitan area of Helsinki, Finland

\begin{tabular}{llll}
\hline & All & Dentists & Teachers \\
\hline $\mathrm{n}(\%)$ & $542(100)$ & $294(54)$ & $248(46)$ \\
Mean (SD) age (years) & $54.0(5.3)$ & $53.7(5.9)$ & $54.3(4.4)$ \\
Mean (SD) BMl (kg/m²) & $24.5(3.6)$ & $23.9(3.2)$ & $25.1(3.9)$ \\
Hand OA cases (\%) & $160(29.5)$ & $72(24.5)$ & $88(35.5)$ \\
\hline
\end{tabular}


hand OA were significantly older and had higher BMI than those without OA.

The genotype frequencies were in HWE in all of the studied polymorphic loci (Table 2). When adjusted for age, occupation and BMI, two TNF $\alpha$ SNPs ("-1031" and "-863") were associated with hand OA (OR $=1.45,95 \%$ CI 1.01-2.07, $p=0.04$ and $1.55,1.06-2.25, p=0.02$, respectively) (Table 3). Further adjustment for the $I L 1 \beta$ and IL6 SNPs had a negligible effect on the observed point estimates, though improving the estimate's precision ( $p=0.03$ and $p=0.01$, respectively). No statistically significant associations were found between the other two TNF $\alpha$ SNPs and hand OA. Neither were there associations between the SNPs in the IL4R or IL10 and hand OA.

Statistically significant interactions were found between the TNFa "-1031" and IL4R Ser503Pro SNPs,

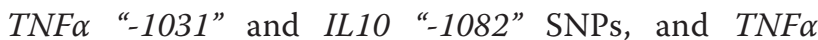
“-863" and IL10 "-1082" SNPs and hand OA ( $p=0.012$, $p=0.0068$, and $p=0.02$, respectively). The carriage of the TNF ("-1031") minor allele was associated with a double risk of hand OA $(2.01,1.26$ - 3.22) in women with the IL4R Ser/Ser genotype (Table 4). Similarly, the TNF $\alpha$ "-1031" and "-863" minor alleles were associated with an increased risk of hand OA only in IL1O G/G or A/A homozygotes $(2.54,1.45-4.47$ and $2.60,1.46-4.62$, respectively) but not in heterozygotes (G/A).

We also examined the individual and joint effects of the TNF $\alpha$ "-863", IL1 $\beta$, and IL6 polymorphisms on hand OA. The risk of hand OA was the highest in the carriers of the minor alleles in all three genes (4.37, 1.84-10.38, $p=0.001)$. Somewhat lower risks were observed for carriers of the $T N F \alpha$ "-863" minor allele $(3.73,1.28-10.85$, $p=0.016)$ and carriers of minor alleles of $I L 1 \beta$ and $I L 6$ SNPs $(2.89,1.29-6.48, p=0.010)$.

The degree of pairwise LD between three TNF $\alpha$ SNPs ("-1031", “-863", and "-308") was high; the "-1031" and “-863” SNPs were in complete linkage ( $D^{\prime}=1, \mathrm{r}^{2}=0.93$, $p<0.0001)$, and the IL4R Ser503Pro and Ser752Ala polymorphisms were also in a strong $L D\left(D^{\prime}=0.998\right.$, $\left.\mathrm{r}^{2}=0.48, p<0.0001\right)$. The three TNF $\alpha$ promoter polymorphisms composed a total of four haplotypes. The most common of these haplotypes was T-C-G (0.69), followed by G-A-G (0.16), T-C-A (0.13), and G-C-G (0.02). The two $I L 4 R$ polymorphisms, on the other hand, composed three haplotypes, i.e., Ser-Ser (0.87), Ser-Pro (0.10) and Ala-Pro (0.03).

The TNF $\alpha$ G-A-G haplotype was associated with an increased risk of hand $\mathrm{OA}$ when adjusted for age, occupation, and BMI (1.61, 1.10-2.37, $p=0.01$ ) (Table 5). There was no difference between participants with and without hand OA in the ILAR haplotype distribution.

\section{Discussion}

We investigated whether the TNF $\alpha$ promoter polymorphisms are associated with hand OA among Finnish women. The minor alleles of the TNF $\alpha$ "-1031" and "-863" loci, as well as their haplotype, were found to be associated with an increased risk of hand OA. The observed associations were independent of the variants in the $I L 1 \beta$ and $I L 6$ genes. Furthermore, our findings suggest that the effect of $T N F \alpha$ polymorphisms on hand OA is modified by the variants within the ILAR and ILIO genes.

A traditional paradigm of OA as a "wear and tear" disease leading to the loss of cartilage has been revised.

Table 2 Description of studied SNPs

\begin{tabular}{|c|c|c|c|c|c|c|c|c|c|c|c|c|c|c|c|}
\hline \multirow[t]{3}{*}{ Genes } & \multirow[t]{3}{*}{ Localization } & \multirow[t]{3}{*}{ SNP ID } & \multirow[t]{3}{*}{ Chro. } & \multirow[t]{3}{*}{ Position } & \multicolumn{10}{|c|}{ MAF } & \multirow{3}{*}{$\begin{array}{l}\text { HWE } \\
\text { p-value in } \\
\text { controls }\end{array}$} \\
\hline & & & & & \multicolumn{2}{|c|}{$\begin{array}{l}\text { Total } \\
(n=1084)\end{array}$} & \multicolumn{2}{|c|}{$\begin{array}{l}\text { OA Cases } \\
(n=320)\end{array}$} & \multicolumn{2}{|c|}{$\begin{array}{l}\text { OA Controls } \\
(n=764)\end{array}$} & \multicolumn{2}{|c|}{$\begin{array}{l}1000 \text { Genomes } \\
\text { Finland\# } \\
(n=186)\end{array}$} & \multicolumn{2}{|c|}{$\begin{array}{l}\text { HapMapa } \\
(n=226)\end{array}$} & \\
\hline & & & & & $\%$ & $n$ & $\%$ & $n$ & $\%$ & $\mathrm{n}$ & $\%$ & $\mathrm{n}$ & $\%$ & $\mathrm{n}$ & \\
\hline TNFa & -1031 & rs1799964 & 6 & 31542308 & 18 & 191 & 21 & 66 & 16 & 125 & 19 & 35 & 21 & 48 & 0.41 \\
\hline$T N F a$ & -863 & rs1800630 & 6 & 31542476 & 16 & 168 & 19 & 60 & 14 & 108 & 15 & 27 & 15 & 34 & 0.79 \\
\hline TNFa & -857 & rs1799724 & 6 & 31542482 & 6.4 & 69 & 5.6 & 18 & 6.7 & 51 & 6.5 & 12 & $\mathrm{NA} / 5.9^{*}$ & 10 & 0.81 \\
\hline TNFa & -308 & rs1800629 & 6 & 31543031 & 13 & 144 & 15 & 47 & 13 & 97 & 13 & 24 & 17 & 39 & 0.59 \\
\hline IL4R & Ser752Ala & rs1805016 & 16 & 27374927 & 3.2 & 35 & 4.1 & 13 & 2.9 & 22 & 5.4 & 10 & 6.3 & 14 & 0.56 \\
\hline IL4R & Ser503Pro & rs1805015 & 16 & 27374180 & 13 & 139 & 14 & 44 & 12 & 95 & 15 & 27 & 15 & 34 & 0.17 \\
\hline $1 L 10$ & -1082 & rs1800896 & 1 & 206946897 & 42 & 453 & 42 & 133 & 42 & 320 & 39 & 73 & 47 & 120 & 0.84 \\
\hline$\| L 1 \beta$ & 3954 & rs1143634 & 2 & 113590390 & 27 & 294 & 31 & 98 & 26 & 196 & 24 & 44 & 21 & 47 & 0.97 \\
\hline IL6 & 174 & rs1800795 & 7 & 22766645 & 44 & 475 & 48 & 153 & 42 & 322 & 44 & 82 & 47 & 105 & 0.88 \\
\hline
\end{tabular}

\#1000 genomes European sub-population, Finnish in Finland.

aHapMap population is CEU: Utah residents with Northern and Western European ancestry from the CEPH collection.

*1000 genomes, population is CEU: Utah residents (CEPH) with Northern and Western European ancestry, $\mathrm{n}=170$.

SNP single nucleotide polymorphism, MAF minor allele frequency, HWE Hardy-Weinberg equilibrium, OA osteoarthritis. 
Table 3 Association of the variants in the cytokine genes with hand OA

\begin{tabular}{|c|c|c|c|c|c|c|}
\hline \multirow[b]{2}{*}{ Genes } & \multirow[b]{2}{*}{ Localization } & \multirow[b]{2}{*}{ SNP ID } & \multicolumn{4}{|c|}{ Hand OA $n=160(542)$} \\
\hline & & & OR $(95 \% \mathrm{Cl})^{1}$ & p-value & OR $(95 \% \mathrm{Cl})^{2}$ & $\mathrm{p}$-value \\
\hline TNFa & -1031 & rs1799964 & $1.45(1.01-2.07)$ & 0.04 & $1.47(1.02-2.13)$ & 0.03 \\
\hline$T N F a$ & -863 & rs1800630 & $1.55(1.06-2.25)$ & 0.02 & $1.61(1.10-2.36)$ & 0.01 \\
\hline TNFa & -857 & rs1799724 & $0.77(0.44-1.35)$ & 0.35 & $0.77(0.44-1.35)$ & 0.36 \\
\hline$T N F a$ & -308 & rs1800629 & $1.25(0.83-1.86)$ & 0.29 & $1.19(0.79-1.79)$ & 0.39 \\
\hline ILAR & Ser752Ala & rs1805016 & $1.41(0.67-2.99)$ & 0.37 & $1.47(0.69-2.32)$ & 0.33 \\
\hline IL4R & Ser503Pro & rs1805015 & $1.17(0.77-1.77)$ & 0.47 & $1.17(0.76-1.78)$ & 0.48 \\
\hline $1 L 10$ & -1082 & rs1800896 & $0.96(0.73-1.27)$ & 0.80 & $0.95(0.71-1.25)$ & 0.70 \\
\hline$\angle L 1 \beta$ & 3954 & rs1143634 & $1.39(1.02-1.88)$ & 0.03 & & \\
\hline $1 L 6$ & 174 & rs1800795 & $1.21(0.92-1.59)$ & 0.18 & & \\
\hline
\end{tabular}

${ }^{1}$ ORs and their $95 \% \mathrm{Cls}$ were adjusted for age, occupation and BMI.

${ }^{2}$ ORs and their $95 \%$ Cls were adjusted for age, occupation, BMI and carriage of the minor allele of the IL1 $\beta$ (rs1143634) or/and IL6 (rs1800795) SNPs. $O A$ osteoarthritis, SNP single nucleotide polymorphism, OR odds ratio, $\mathrm{Cl}$ confidence interval, $B M I$ body mass index.

Nowadays, OA is considered a complex disease with inflammatory mediators released by cartilage, bone and synovium [8]. TNFa is one of the most typical proinflammatory cytokines that along with IL1 $\beta$ is connected with cartilage destruction. These two cytokines, which are

Table 4 Interaction of the TNFa SNPs with the IL4R and IL10 SNPs in their effect on hand OA

\begin{tabular}{|c|c|c|c|c|c|}
\hline & & $\mathrm{n}$ & OR & $95 \% \mathrm{Cl}$ & $\mathrm{p}$-value \\
\hline IL4R & TNFa "-1031" & & & & 0.01 \\
\hline \multirow[t]{2}{*}{ Ser/Ser } & $\mathrm{T} / \mathrm{T}$ & $67 / 270$ & 1.00 & & \\
\hline & $\mathrm{T} / \mathrm{C}-\mathrm{C} / \mathrm{C}$ & $52 / 138$ & 2.01 & $1.26-3.22$ & \\
\hline \multirow[t]{2}{*}{ Ser/Pro-Pro/Pro } & $\mathrm{T} / \mathrm{T}$ & $33 / 94$ & 1.00 & & \\
\hline & $\mathrm{T} / \mathrm{C}-\mathrm{C} / \mathrm{C}$ & $8 / 39$ & 0.55 & $0.22-1.40$ & \\
\hline IL4R & TNFa "-863" & & & & 0.05 \\
\hline \multirow[t]{2}{*}{ Ser/Ser } & $C / C$ & $71 / 285$ & 1.00 & & \\
\hline & $C / A-A / A$ & $33 / 99$ & 2.09 & $1.29-3.27$ & \\
\hline \multirow[t]{2}{*}{ Ser/Pro-Pro/Pro } & $\mathrm{C} / \mathrm{C}$ & $48 / 123$ & 1.00 & & \\
\hline & $C / A-A / A$ & $8 / 34$ & 0.72 & $0.28-1.87$ & \\
\hline IL10 & TNFa "-1031" & & & & 0.007 \\
\hline \multirow[t]{2}{*}{ G/A } & $\mathrm{T} / \mathrm{T}$ & $55 / 175$ & 1.00 & & \\
\hline & $\mathrm{T} / \mathrm{C}-\mathrm{C} / \mathrm{C}$ & 20/83 & 0.80 & $0.43-1.51$ & \\
\hline \multirow[t]{2}{*}{$\mathrm{A} / \mathrm{A}-\mathrm{G} / \mathrm{G}$} & $\mathrm{T} / \mathrm{T}$ & $29 / 120$ & 1.00 & & \\
\hline & $\mathrm{T} / \mathrm{C}-\mathrm{C} / \mathrm{C}$ & $27 / 66$ & 2.54 & $1.45-4.47$ & \\
\hline IL10 & TNFa "-863" & & & & 0.02 \\
\hline \multirow[t]{2}{*}{$\mathrm{G} / \mathrm{A}$} & $C / C$ & $56 / 186$ & 1.00 & & \\
\hline & $C / A-A / A$ & $19 / 72$ & 0.94 & $0.49-1.80$ & \\
\hline \multirow[t]{2}{*}{ A/A-G/G } & $\mathrm{C} / \mathrm{C}$ & $48 / 198$ & 1.00 & & \\
\hline & $C / A-A / A$ & $37 / 85$ & 2.60 & $1.46-4.62$ & \\
\hline
\end{tabular}

Odds ratios (ORs) and $95 \%$ confidence intervals (Cls) are adjusted for age, occupation and body mass index (BMI).

SNP single nucleotide polymorphism, $O A$ osteoarthritis, $O R$ odds ratio, $\mathrm{Cl}$ confidence interval. produced by chondrocytes, mononuclear cells, osteoblasts and synovial tissues, induce the production of a number of inflammatory and catabolic factors [5]. Among the four polymorphic loci studied here, only the TNF " -308 " locus has been shown to affect the TNFa protein levels, the minor allele of the SNP was associated with increased TNF $\alpha$ production in response to various stimuli $[27,28]$. However, also opposite observations, e.g., no effect on the protein levels or lowered protein levels, have been reported $[29,30]$. When studying the above SNPs with F-SNPprogram that is freely available on the internet (http:// compbio.cs.queensu.ca/F-SNP/) connected to the main databases, and computationally predicting functional SNPs, all four SNPs are predicted to be functional as they seem to be in the transcription factor binding site [31]. However, the protein level alteration by the studied SNPs still remains unsolved and needs to be further studied.

The few studies that examined associations between $T N F \alpha$ polymorphisms and knee or hip OA have given

Table 5 Association of haplotypes with hand OA

\begin{tabular}{lllll}
\hline & $\begin{array}{l}\text { OA- } \\
(\mathbf{n = 3 8 2})\end{array}$ & $\begin{array}{l}\text { OA }+ \\
(\mathbf{n}=160)\end{array}$ & OR (95\% Cl) & p-value \\
\hline TNFa-1031-863 -308 & & & & $0.07^{*}$ \\
T-C-G & 0.71 & 0.65 & 1.00 & \\
C-A-G & 0.14 & 0.19 & $1.61(1.10-2.37)$ & 0.01 \\
T-C-A & 0.13 & 0.15 & $1.35(0.89-2.03)$ & 0.16 \\
C-C-G & 0.02 & 0.02 & $0.93(0.33-2.58)$ & 0.88 \\
IL4R & & & & $0.65^{*}$ \\
Ser-Ser & 0.88 & 0.86 & 1.00 & \\
Ser-Pro & 0.10 & 0.10 & $1.08(0.67-1.74)$ & 0.73 \\
Ala-Pro & 0.02 & 0.04 & $1.43(0.67-3.03)$ & 0.37 \\
\hline
\end{tabular}

ORs and their $95 \%$ Cls were adjusted for age, occupation and BMI. ${ }^{*}$ Global haplotype association p-value. 
conflicting results [32]. To our knowledge, this is the first study to report an association between the TNF $\alpha$ variant alleles and hand OA. TNF $\alpha$ can act independently or in concert with other cytokines (e.g., IL1 $\beta$, IL4, IL6, and Il10) to initiate and expand inflammation [5]. Ignorance of the complex interrelationships between pro- and anti-inflammatory cytokines might be the reason for failure to detect an association between the $T N F \alpha$ polymorphisms and OA. It has been suggested that the combined use of information from multiple markers may be more effective to reveal the association between a genomic region and a trait than a single marker analysis [33].

Previously our group reported the associations of the IL1 and IL6 gene polymorphisms with hand OA $[19,20]$. The current findings suggest that TNF $\alpha$ promoter polymorphisms may increase the risk of hand OA independently of the polymorphisms in the IL1 and IL6 genes, and that the effect attributed to combination of variants in all three genes is larger, but less than additive.

When we examined the association of the TNF $\alpha$ polymorphisms with hand OA taking into consideration the variants of other cytokine genes, the IL4R and ILIO polymorphisms appeared to act as effect modifiers.

Vargiolu et al. [34] reported an association of genetic variants in the coding region of the ILAR gene with hand $\mathrm{OA}$ among men and women in the age range of 41 to 84 years. However, we failed to replicate this association among our participants. Differences between the study populations, OA phenotypes, and minor allele frequencies might be the reasons for discrepancies in the findings. Our participants were younger (mean age 53 years) than in the study by Vargiolu and coworkers, which may partly explain the difference of the prevalence of hand OA between their and our study $(55.6 \%$ and $29.5 \%$, respectively).

Naturally occurring anti-inflammatory cytokines such as IL10 inhibit the synthesis of IL1 and TNF $\alpha$ [13]. The IL10 “-1082" polymorphism has been shown to affect the level of the protein production: the A-allele is connected with a significantly higher protein production than the G-allele [35]. This polymorphism was also associated with rheumatoid arthritis in a meta-analysis [36]. As to its role in DIP OA, no association was found in the Dutch population [37]. Similarly, the IL10 "-1082" did not associate with hand OA in our study.

A major strength of the study was that all study participants were of the ethnically relatively homogenous Finnish origin. Each ethnic group has its own set of environmental and genetic factors that contribute to the disease risk, and differences in allelic frequency often affect our ability to detect a susceptibility allele. The Finnish population is known to be a genetic isolate, which originated from a small founder population some
2000 years ago. Therefore, the Finnish population with the relatively homogenous gene pool [38] offers an optimal material for association studies.

Another strength of our study is that we analyzed haplotypes in addition to SNPs. Grouping of SNPs in haplotypes generally leads to a stronger association with the phenotype than individual polymorphisms.

Further, the prevalence of hand OA was similar to that seen in other studies [39-41], and major potential confounders were controlled for in the statistical analyses.

A limitation of our study is the relatively small number of participants, leading to reduced power to detect small effects and an increased likelihood of spurious findings. This needs to be considered while interpreting the observed associations. Another obvious limitation is the fact that our study participants were all women and consequently the results cannot be generalized to men.

\section{Conclusions}

Our results suggest that variants in the TNF $\alpha$ gene play a role in the etiology of hand OA in Finnish women. In addition, the findings are suggestive of a gene-gene interaction of the TNF $\alpha$ with the $I L 4 R$ and $I L 10$ genes. However, these findings should be considered with caution until replicated in other study population.

\section{Additional file}

Additional file 1: Detailed protocols for genotyping.

\section{Abbreviations}

TNFa: Tumor necrosis factor alpha; IL6: Interleukine 6; IL1: Interleukine 1; OA: Osteoarthritis; BMl: Body mass index; PCR: Polymerase chain reaction; SNP: Single nucleotide polymorphism; DIP: Distal interphalangeal; PIP: Proximal interphalangeal; IP: Interphalangeal; IL1B: Interleukin 1, beta; K-L: Kellgren and Lawrence; RFLP: Restriction fragment length polymorphism; HWE: HardyWeinberg equilibrium; LD: Linkage disequilibrium; OR: Odds ratio; $\mathrm{Cl}$ : Confidence interval; MHC: Major histocompatibility complex.

\section{Competing interests}

The authors declare that they have no competing interests.

\section{Authors' contributions}

SH carried the main responsibility of the design and performance of the genotyping and data analyses, and preparation of the manuscript; SS participated in the study design, data collection, the design of the data analyses, the interpretation of the results, and preparation of the manuscript; TV participated in the data collection, radiological examinations, data analysis, and preparation of the manuscript; PL-A carried the main responsibility of the overall study design, and participated in the data collection and preparation of the manuscript; $\mathrm{AH}$ participated in the conception and design of the study, the interpretation of the data, and preparation of the manuscript. All authors have read and approved the final version of the manuscript.

\section{Acknowledgements}

We are grateful to Katariina Luoma, MD (University of Helsinki, Helsinki University Central Hospital, Radiology department, Finland), for performing the second readings of the hand radiographs for reliability analysis. We are also grateful to Sirpa Hyttinen and Mari Kukkonen for referring the genotyping results and the input of the data to the database, and Susanna Lemmelä for valuable advice in the preparation of the manuscript. The study was financially supported by a 
grant from the Finnish Work Environment Fund (101334) and grant from National Doctoral Programme of Musculoskeletal Disorders and Biomaterials (TBDP). The study sponsors had no role in the study design, collection, analysis and interpretation of data, in the writing of the manuscript, or in the decision to submit the manuscript for publication

Received: 10 May 2014 Accepted: 19 September 2014 Published: 24 September 2014

\section{References}

1. Bijlsma JW, Berenbaum F, Lafeber FP: Osteoarthritis: an update with relevance for clinical practice. Lancet 2011, 377(9783):2115-2126.

2. Loeser RF: Age-related changes in the musculoskeletal system and the development of osteoarthritis. Clin Geriatr Med 2010, 26(3):371-386.

3. Kalichman L, Hernandez-Molina G: Hand osteoarthritis: an epidemiological perspective. Semin Arthritis Rheum 2010, 39(6):465-476.

4. Arden N, Nevitt MC: Osteoarthritis: epidemiology. Best Pract Res Clin Rheumatol 2006, 20(1):3-25.

5. Kapoor M, Martel-Pelletier J, Lajeunesse D, Pelletier JP, Fahmi H: Role of proinflammatory cytokines in the pathophysiology of osteoarthritis. Nat Rev Rheumatol 2011, 7(1):33-42

6. Farahat MN, Yanni G, Poston R, Panayi GS: Cytokine expression in synovial membranes of patients with rheumatoid arthritis and osteoarthritis. Ann Rheum Dis 1993, 52(12):870-875.

7. Sellam J, Berenbaum F: The role of synovitis in pathophysiology and clinical symptoms of osteoarthritis. Nat Rev Rheumatol 2010, 6(11):625-635

8. Berenbaum F: Osteoarthritis as an inflammatory disease (osteoarthritis is not osteoarthrosis!). Osteoarthritis Cartilage 2013, 21(1):16-21.

9. Krasnokutsky S, Attur M, Palmer G, Samuels J, Abramson SB: Current concepts in the pathogenesis of osteoarthritis. Osteoarthritis Cartilage 2008, 16(Suppl 3):S1-S3,

10. Pelletier JP, Martel-Pelletier J, Abramson SB: Osteoarthritis, an inflammatory disease: potential implication for the selection of new therapeutic targets. Arthritis Rheum 2001, 44(6):1237-1247.

11. Martel-Pelletier J, Alaaeddine N, Pelletier JP: Cytokines and their role in the pathophysiology of osteoarthritis. Front Biosci 1999 4:D694-D703.

12. Page Thomas DP, King B, Stephens T, Dingle JT: In vivo studies of cartilage regeneration after damage induced by catabolin/interleukin-1. Ann Rheum Dis 1991, 50(2):75-80.

13. Fernandes JC, Martel-Pelletier J, Pelletier JP: The role of cytokines in osteoarthritis pathophysiology. Biorheology 2002, 39(1-2):237-246.

14. Malemud CJ, Islam N, Haqqi TM: Pathophysiological mechanisms in osteoarthritis lead to novel therapeutic strategies. Cells Tissues Organs 2003, 174(1-2):34-48.

15. Hajeer $\mathrm{AH}$, Hutchinson IV: TNF-alpha gene polymorphism: clinical and biological implications. Microsc Res Tech 2000, 50(3):216-228.

16. Millward-Sadler SJ, Wright MO, Lee H, Nishida K, Caldwell H, Nuki G, Salter DM: Integrin-regulated secretion of interleukin 4: A novel pathway of mechanotransduction in human articular chondrocytes. J Cell Biol 1999, 145(1):183-189.

17. Salter DM, Millward-Sadler SJ, Nuki G, Wright MO: Integrin-interleukin-4 mechanotransduction pathways in human chondrocytes. Clin Orthop Relat Res 2001, Oct(391 Suppl):S49-S60.

18. Ryder JJ, Garrison K, Song F, Hooper L, Skinner J, Loke Y, Loughlin J, Higgins JP, MacGregor AJ: Genetic associations in peripheral joint osteoarthritis and spinal degenerative disease: a systematic review. Ann Rheum Dis 2008, 67(5):584-591.

19. Solovieva S, Kamarainen OP, Hirvonen A, Hamalainen S, Laitala M, Vehmas $T$, Luoma K, Nakki A, Riihimaki H, Ala-Kokko L, Mannikko M, Leino-Arjas P: Association between interleukin 1 gene cluster polymorphisms and bilateral distal interphalangeal osteoarthritis. J Rheumatol 2009, 36(9):1977-1986.

20. Kamarainen OP, Solovieva S, Vehmas T, Luoma K, Riihimaki H, Ala-Kokko L, Mannikko M, Leino-Arjas P: Common interleukin-6 promoter variants associate with the more severe forms of distal interphalangeal osteoarthritis. Arthritis Res Ther 2008, 10(1):R21.

21. Kellgren $\mathrm{JH}$, Lawrence JS: Radiological assessment of osteo-arthrosis Ann Rheum Dis 1957, 16(4):494-502
22. Solovieva S, Vehmas T, Riihimaki H, Luoma K, Leino-Arjas P: Hand use and patterns of joint involvement in osteoarthritis. A comparison of female dentists and teachers. Rheumatology (Oxford) 2005, 44:521-528.

23. Ozen S, Alikasifoglu M, Bakkaloglu A, Duzova A, Jarosova K, Nemcova D, Besbas N, Vencovsky J, Tuncbilek E: Tumour necrosis factor alpha G $\rightarrow$ A 238 and $\mathrm{G} \rightarrow \mathrm{A} 308$ polymorphisms in juvenile idiopathic arthritis. Rheumatology (Oxford) 2002, 41(2):223-227.

24. Koch W, Kastrati A, Bottiger C, Mehilli J, von Beckerath N, Schomig A Interleukin-10 and tumor necrosis factor gene polymorphisms and risk of coronary artery disease and myocardial infarction. Atherosclerosis 2001, 159(1):137-144

25. Sole X, Guino E, Valls J, Iniesta R, Moreno V: SNPStats: a web tool for the analysis of association studies. Bioinformatics 2006, 22(15):1928-1929.

26. Sidak Z: Rectangular Confidence Regions for the Means of Multivariate Normal Distributions. J Am Stat Assoc 1967, 62(318):626-633.

27. Higuchi T, Seki N, Kamizono S, Yamada A, Kimura A, Kato H, Itoh K Polymorphism of the 5 '-flanking region of the human tumor necrosis factor (TNF)-alpha gene in Japanese. Tissue Antigens 1998, 51(6):605-612.

28. Wilson AG, Symons JA, McDowell TL, McDevitt HO, Duff GW: Effects of a polymorphism in the human tumor necrosis factor alpha promoter on transcriptional activation. Proc Natl Acad Sci U S A 1997, 94(7):3195-3199.

29. Mekinian A, Tamouza R, Pavy S, Gestermann N, Ittah M, Mariette X, MiceliRichard C: Functional study of TNF-alpha promoter polymorphisms: literature review and meta-analysis. Eur Cytokine Netw 2011, 22(2):88-102.

30. Sharma S, Sharma A, Kumar S, Sharma SK, Ghosh B: Association of TNF haplotypes with asthma, serum IgE levels, and correlation with serum TNF-alpha levels. Am J Respir Cell Mol Biol 2006, 35(4):488-495.

31. Lee PH, Shatkay H: F-SNP: computationally predicted functional SNPs for disease association studies. Nucleic Acids Res 2008, 36(Database issue): D820-D824.

32. Han L, Song JH, Yoon JH, Park YG, Lee SW, Choi YJ, Nam SW, Lee JY, Park WS: TNF-alpha and TNF-beta Polymorphisms are Associated with Susceptibility to Osteoarthritis in a Korean Population. Korean J Patho/ 2012, 46(1):30-37.

33. Gauderman WJ, Murcray C, Gilliland F, Conti DV: Testing association between disease and multiple SNPs in a candidate gene. Genet Epidemiol 2007, 31(5):383-395.

34. Vargiolu M, Silvestri T, Bonora E, Dolzani P, Pulsatelli L, Addimanda O, Mancarella L, Punzi L, Fioravanti A, Facchini A, Romeo G, Meliconi R: Interleukin-4/interleukin-4 receptor gene polymorphisms in hand osteoarthritis. Osteoarthritis Cartilage 2010, 18(6):810-816.

35. Turner DM, Williams DM, Sankaran D, Lazarus M, Sinnott PJ, Hutchinson IV: An investigation of polymorphism in the interleukin-10 gene promoter. Eur J Immunogenet 1997, 24(1):1-8.

36. Zhang J, Zhang Y, Jin J, Li M, Xie K, Wen C, Cheng R, Chen C, Lu J: The $-1082 \mathrm{~A} / \mathrm{G}$ polymorphism in the Interleukin-10 gene and the risk of rheumatoid arthritis: a meta-analysis. Cytokine 2011, 56(2):351-355.

37. Riyazi N, Kurreeman FA, Huizinga TW, Dekker FW, Stoeken-Rijsbergen G, Kloppenburg M: The role of interleukin 10 promoter polymorphisms in the susceptibility of distal interphalangeal osteoarthritis. J Rheumatol 2005, 32(8):1571-1575.

38. Peltonen $L$, Jalanko A, Varilo T: Molecular genetics of the Finnish disease heritage. Hum Mol Genet 1999, 8(10):1913-1923.

39. van Saase JL, van Romunde LK, Cats A, Vandenbroucke JP, Valkenburg HA: Epidemiology of osteoarthritis: Zoetermeer survey. Comparison of radiological osteoarthritis in a Dutch population with that in 10 other populations. Ann Rheum Dis 1989, 48(4):271-280.

40. Sowers M, Lachance L, Hochberg M, Jamadar D: Radiographically defined osteoarthritis of the hand and knee in young and middle-aged African American and Caucasian women. Osteoarthritis Cartilage 2000, 8(2):69-77.

41. Haara MM, Manninen $P$, Kroger $H$, Arokoski JP, Karkkainen A, Knekt $P$, Aromaa A, Heliovaara M: Osteoarthritis of finger joints in Finns aged 30 or over: prevalence, determinants, and association with mortality. Ann Rheum Dis 2003, 62(2):151-158.

doi:10.1186/1471-2474-15-311

Cite this article as: Hämäläinen et al:: Variations in the TNFa gene and their interactions with the IL4R and IL 10 genes in relation to hand osteoarthritis. BMC Musculoskeletal Disorders 2014 15:311. 